\title{
Article \\ Developing Physics Experiments Using Augmented Reality Game-Based Learning Approach: A Pilot Study in Primary School
}

\author{
Maria Zafeiropoulou (D), Christina Volioti, Euclid Keramopoulos and Theodosios Sapounidis *(D) \\ Department of Information and Electronic Engineering, International Hellenic University, \\ 57001 Nea Moudania, Greece; mariazaf1996@gmail.com (M.Z.); chvolioti@gmail.com (C.V.); euclid@ihu.gr (E.K.) \\ * Correspondence: teo@edlit.auth.gr
}

check for updates

Citation: Zafeiropoulou, M.; Volioti, C.; Keramopoulos, E.; Sapounidis, T. Developing Physics Experiments Using Augmented Reality Game-Based Learning Approach: A Pilot Study in Primary School. Computers 2021, 10, 126. https://doi.org/10.3390/ computers10100126

Academic Editors: Carlos Vaz de Carvalho and Antonio Coelho

Received: 9 September 2021

Accepted: 7 October 2021

Published: 11 October 2021

Publisher's Note: MDPI stays neutral with regard to jurisdictional claims in published maps and institutional affiliations.

Copyright: (c) 2021 by the authors. Licensee MDPI, Basel, Switzerland. This article is an open access article distributed under the terms and conditions of the Creative Commons Attribution (CC BY) license (https:// creativecommons.org/licenses/by/ $4.0 /)$.

\begin{abstract}
The augmented reality game-based learning (ARGBL) approach is an advantageous pathway for the development and enhancement of teaching and learning processes. To this end, this paper presents the design and development of an ARGBL application for the implementation of physics experiments in the fifth grade of a Greek primary school. The purpose of the ARGBL system is twofold: to educate and entertain. For this reason, a treasure hunt game was implemented, which allows students to interact with a digital world and to manipulate virtual objects with the use of an augmented reality (AR) device. Then, according to the instructions, students have to collect all the materials to conduct the AR educational experiment. Overall, the evaluation of the system's usability by 17 users (both students and teachers) was very promising, indicating that the ARGBL application has the potential to be an easy-to-use educational tool for improving not only the teaching of physics experiments in primary school but also the learning process, by positively affecting the students' motivation and engagement.
\end{abstract}

Keywords: augmented reality; game-based learning; usability; primary school; physics

\section{Introduction}

Azuma [1] defined augmented reality (AR) as a technology by which users can integrate $3 \mathrm{D}$ virtual objects in real time into their real-world environment. AR is a popular technology that is used in many aspects of our lives [2,3]. The basic reason for its popularity is that it has no special equipment requirements as in virtual reality. A smart device (tablet or smartphone) is enough. Moreover, recently, large companies in the field of information technology, such as Google and Apple, have delivered suitable frameworks and APIs to programmers, in order to develop a high quality of augmented reality applications, such as ARCore [4], ARKIT [5] and libraries for Unity [6].

For the last decade, augmented reality has been used in research to improve the educational process at all levels of education from primary education to university [7]. A remarkable number of augmented reality applications have been created, which basically augment the content of a schoolbook mainly using text, pictures and video [8,9]. Field experiments using AR application in education have shown that the education process was improved by increasing the fun, enjoyment, interest and engagement of students [7]. Furthermore, another interesting approach that has gained attention in education science is augmented reality game-based learning (ARGBL), which can transform the learning experience and influence students' motivation, skill development and knowledge [10]. Apart from the learning process, AR and ARGBL technology can additionally benefit the teaching process. Teachers who integrate such innovative approaches into the teaching process can introduce and explain to students complex and/or abstract concepts through a multisensory way, encouraging social interaction and improving collaboration [7,11]. All in all, AR and ARGBL can be successfully used in educational environments, positively 
affecting both the teaching and the learning process, since (a) the cost of materials for the experiment disappears (sometimes a big problem for the education procedure [11]), (b) the experiment can be repeated as many times as the educational process requires (without the thought of wasting materials) and, most importantly, (c) the student can repeat the experiment when studying the course at home.

In this paper, an ARGBL approach was introduced for teaching the experimental part of a lesson of physics in the fifth grade of a Greek primary school. In particular, an application is presented that is based on ARGBL for the development of all the experiments for the unit of physics in the fifth grade of a Greek primary school. The contribution of this research is multifaceted. The case study focuses on lab/practical experiments in a unit such as physics, by adopting a game-based approach, which, according to the literature review, has found limited implementation in primary schools. All the experiments can be executed using an ordinary smart device such as a smartphone or a tablet. Additionally, the applications were designed to be interactive. This was conducted using game-based learning, where students are invited with a treasure hunt game to discover the materials of the experiment in one place. Thus, they are "forced" to pay attention to the materials used for the experiment. Then, after "accomplishing the mission" of finding all the materials, they can "run" the experiment as many times as they want until all the questions regarding the experiment and the physics topic are answered. We used the ARGBL application to perform a pilot experiment in a primary school, where the results were very satisfactory and showed that this approach greatly improves the educational process as it increases the fun, enjoyment, engagement and interest in the course.

This paper is organized as follows. In Section 2, AR and ARGBL are introduced. In Section 3, a short review is presented regarding the use of AR and ARGBL in physical science in both primary and secondary school. Next, in Section 4, the description of the suite of applications is analyzed, and in Section 5, the pilot experiment and its results are presented. In Section 6, the discussion of the research work is analyzed, and finally, in Section 7 , the conclusions as well as future work are presented.

\section{Augmented Reality Game-Based Learning}

AR is an emerging technology, which has great potential. Although the first AR applications appeared in the late 1960s [12], it has become more pervasive and affordable in recent years due to the widespread use of mobile devices [13]. AR essentially blends virtual worlds into real ones, by allowing the user to explore, manipulate and interact in a seamless way with both digital and natural objects in real time [14,15]. Additionally, it allows them to envision objects in different situations and receive immediate visual feedback about their actions in a totally safe environment [12]. Therefore, AR improves learners' ability to understand abstract and complex concepts [16], since it can provide enriched experiential and in situ learning experiences [12].

Another learning approach that takes advantage of experiential learning theory is game-based learning (GBL), which uses specially designed games to improve the learning process [17]. One of the advantages of GBL is that through games, users construct their own knowledge and develop the ability to transfer it to other contexts, rather than passively absorbing a new concept, a pillar that the traditional educational process supports [18]. Therefore, of particular relevance to the education sector are the two aforementioned pedagogical approaches which both enhance the learning experience and learners' effectiveness by actively engaging them.

The term ARGBL, which is basically the integration of AR into GBL, is gaining more and more pace nowadays. According to Pellas et al.'s [19] systematic review, some of the most popular domains of ARGBL use in primary and secondary school education are formal science [20-23], natural science [24-27], physical science [15,28-31] and social science [32-34]. Additionally, problem solving, performance, motivation, satisfaction, creativity and collaboration [33] are, among others, benefits of ARGBL in the learning experience. 


\section{Review}

Several previous studies have been conducted to explore the use, benefits and limitations or challenges of AR and ARGBL at all levels of education in the domain of physical science (such as physics, astronomy and chemistry). More specifically, Enyedy et al. [15] developed an AR environment to teach Newtonian force and motion to young children, 6-8 years old. During the activity, children had to predict how the forces would influence the motion of an object (e.g., ball). The results showed that children made significant progress in learning the content and improved their performance, since they engaged, explored and reconstructed their conceptual knowledge through fruitful confrontation and discussion. Additionally, Cai et al. [28] conducted a convex imaging experiment using AR technology, in which the eighth graders explored basic concepts of physics (such as image distance and focal distance) as well as abstract ones (such as what will happen when the object moves closer to the lens). The findings revealed that the AR tool attracted their attention, stimulated their interest and enhanced their learning. A few years later, Cai et al. [29] implemented a system that integrates AR with natural interaction technology by using Kinect, in teaching magnetic fields to students in grade 8. Students could trigger the magnetic field in real time with a wave of their hand in front of the depth camera. The experimental results stated that the system encouraged participants to learn more extensively through a more intuitive way, by activating their motivation and interest in learning.

Regarding astronomy, Zhang et al. [30] designed an AR-based mobile digital armillary sphere for astronomy. An intervention was organized for fifth grade elementary school students, and the purpose was to examine if they could properly identify the constellations through astronomical observation. The analysis indicated that the observation tool, which is based on kinesthetic-style strategies, positively affected participants' motivation and engagement as well as improving their learning experience and observation skills.

Finally, Cai et al. [31] proposed an AR simulation system in which students could control particles in micro-worlds and compose substances. This study was conducted in a junior high school for the chemistry course. Through data analysis, the authors concluded that the AR tool improved the learning outcome and helped students to develop different skills such as problem solving and inquiry-based exploration skills.

Leveraging the aforementioned studies, AR and ARGBL have proved to be advantageous in enhancing performance and learning experiences, developing skills (e.g., problem solving, inquiry-based exploration, observation) and fostering motivation, engagement, attention and interest. Moreover, through AR, students can learn and interact with virtual and real objects in a more intuitive way. Therefore, teachers should integrate such innovative applications which place emphasis on the design of more natural and realistic representations of complicated problems of everyday life into the educational process. However, AR and ARGBL pose some limitations and challenges. Due to the technologies' novelty, proper training and guidance should be provided to both students and teachers [29]. In addition, according to Tobar-Muñoz et al. [35], sometimes there is a gap between designers and teachers in conceiving learning. It is thus important to involve both designers and teachers in the design and development of such AR tools, in order to create a proper learning experience in the classroom that would be only beneficial.

\section{Application Description}

An ARGBL application for the physics course of the fifth grade in a primary school was developed and evaluated in the present paper. The application follows the new technological developments of smart mobile devices and introduces the concept of AR to the students. Since the purpose of the ARGBL application is both to educate and entertain, a treasure hunt game was implemented, which allows students to interact with a digital world and to manipulate virtual objects with the use of an AR device. They have to discover all the materials in order to conduct the AR experiment, according to the instructions that correspond to each experiment. 


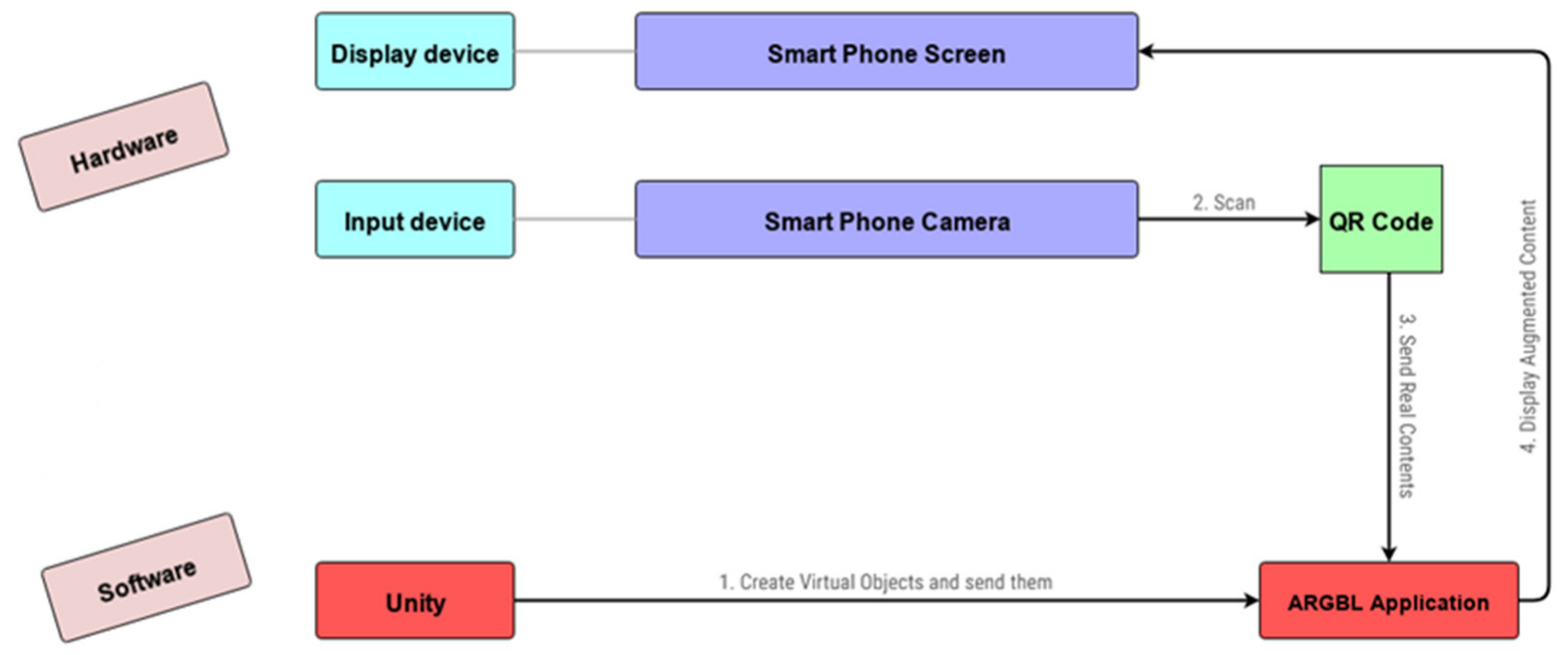

\subsection{System Overview}

In this section, the system overview of the ARGBL application is presented. The system consists of the following components: (a) a smartphone device (hardware), and (b) the Unity platform (software), as shown in Figure 1. More analytically, the ARGBL application was implemented using the free version of the Unity game engine and C\# as the programming language. The Unity platform was chosen because Unity software is powerful, easy to use and free [36]. Vuforia SDK was also used to ensure a better AR experience. At first, Unity sends the virtual content to the ARGBL application. Then, the input device, which is the camera of the smartphone, scans the QR code of the textbook and sends the real content to the ARGBL application. Subsequently, the ARGBL application processes the virtual and the real contents and finally displays the augmented content through the smartphone screen, which is the display device.

Figure 1. Application components.

In Unity, there is a set of elements which together form a game. These elements play a major role in making the game interactive as well as adding features that can vividly express the objective of the game. The proposed ARGBL application includes the following elements: 41 scenes, 88 scripts, 17 packages, hundreds of assets and thousands of 3D gameobjects and prefabs.

\subsection{Suite of Applications}

The suite of applications is a collection of six experiments, where each experiment corresponds to one of the six chapters of the fifth grade textbook. According to the curriculum of the 2019-2020 school year, the chapters are: (a) material bodies, (b) energy, (c) digestive system, (d) heat, (e) electricity and (f) light. More analytically, on the start screen (Scene 1), there are six buttons which correspond to the chapters of the book (Figure 2). By selecting a chapter, the application sends the user to the next scene (Scene 2), which is composed of the available experiment. 


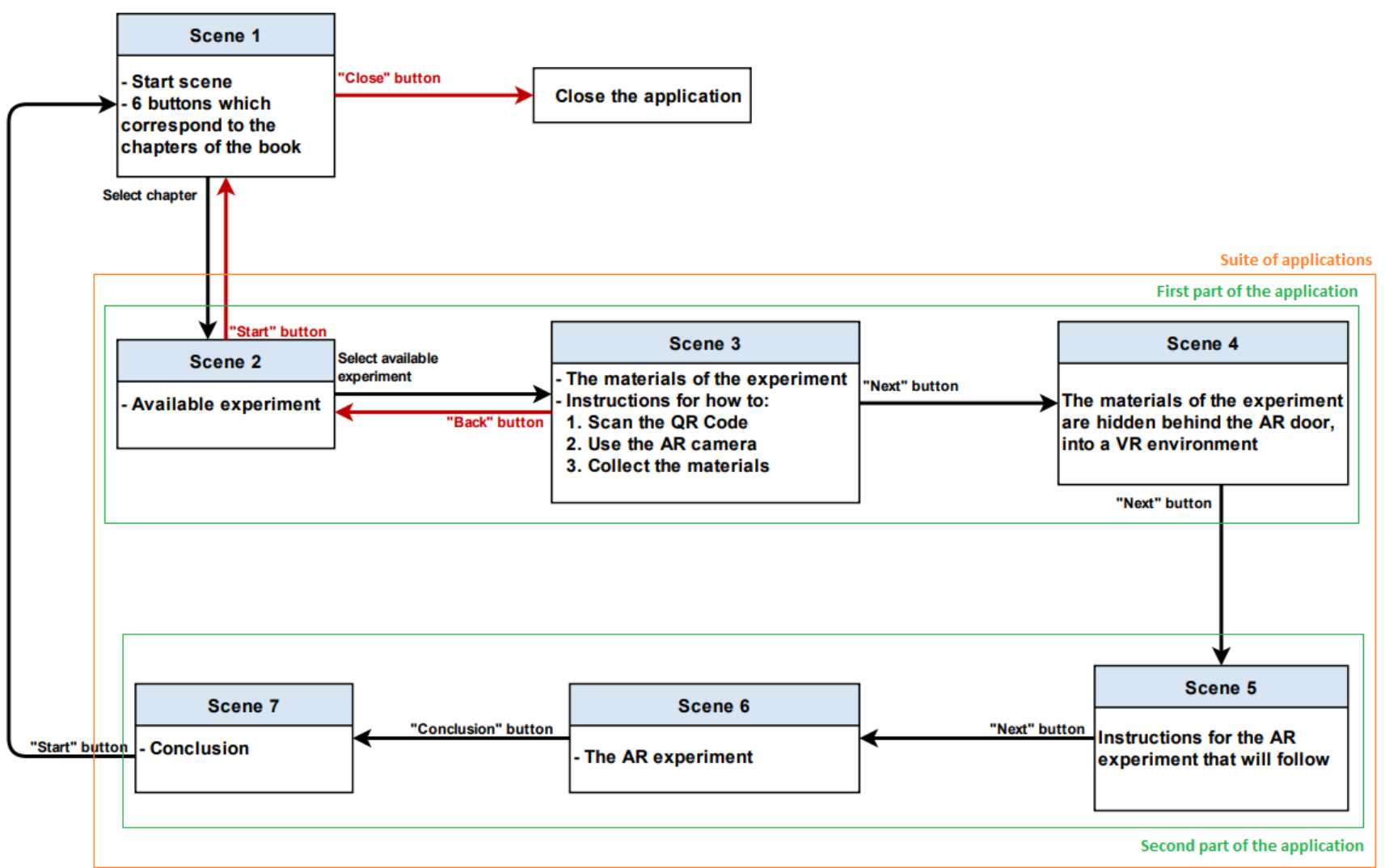

Figure 2. Application sub-components.

According to the student's choice, instructions are displayed (Scene 3) about how the experiment will be performed using the AR technology. In the next scene (Scene 4), the camera of the user's device is activated, and by scanning the QR code of the textbook page where the experiment is located, an AR door appears. Entering the door, the user is immersed into a VR environment. There are hidden virtual objects that must be collected in order for the educational experiment to be implemented, by using AR. At the bottom of the screen, there is a list with all the materials of the experiment which are hidden behind the AR door. In order for the user to proceed with the experiment, they must first collect all the materials by clicking on them in the VR world. Then, the materials are automatically checked in the list. It is basically a treasure hunt game, representing the first part of the ARGBL application which is for entertainment purposes.

Once the student has collected all the necessary materials for the experiment, instructions for the experiment that will be followed are displayed (Scene 5). After scanning the QR code of the textbook page for the selected chapter again, the available experiment is displayed (Scene 6). The available experiments are performed differently by the user, meaning that each experiment has a different process, instructions and learning outcomes. Moreover, with the teacher's guidance, a fruitful discussion takes place in order for students to draw a conclusion. At the bottom of the screen, there is the "conclusion" button which leads the student to the next and the last screen (Scene 7), which consists of the conclusion. This represents the second part of the application which is for educational purposes.

\subsubsection{Experiments}

As already mentioned, six (6) experiments were formulated, and each one consists of Scenes 2-7 (Figure 2). Scenes 2, 3, 5 and 7 are almost the same in all experiments, with minor changes in their content. The scenes that differ are Scene 4 and Scene 6 . Table 1 analytically describes the process of each experiment. 
Table 1. Process of each experiment.

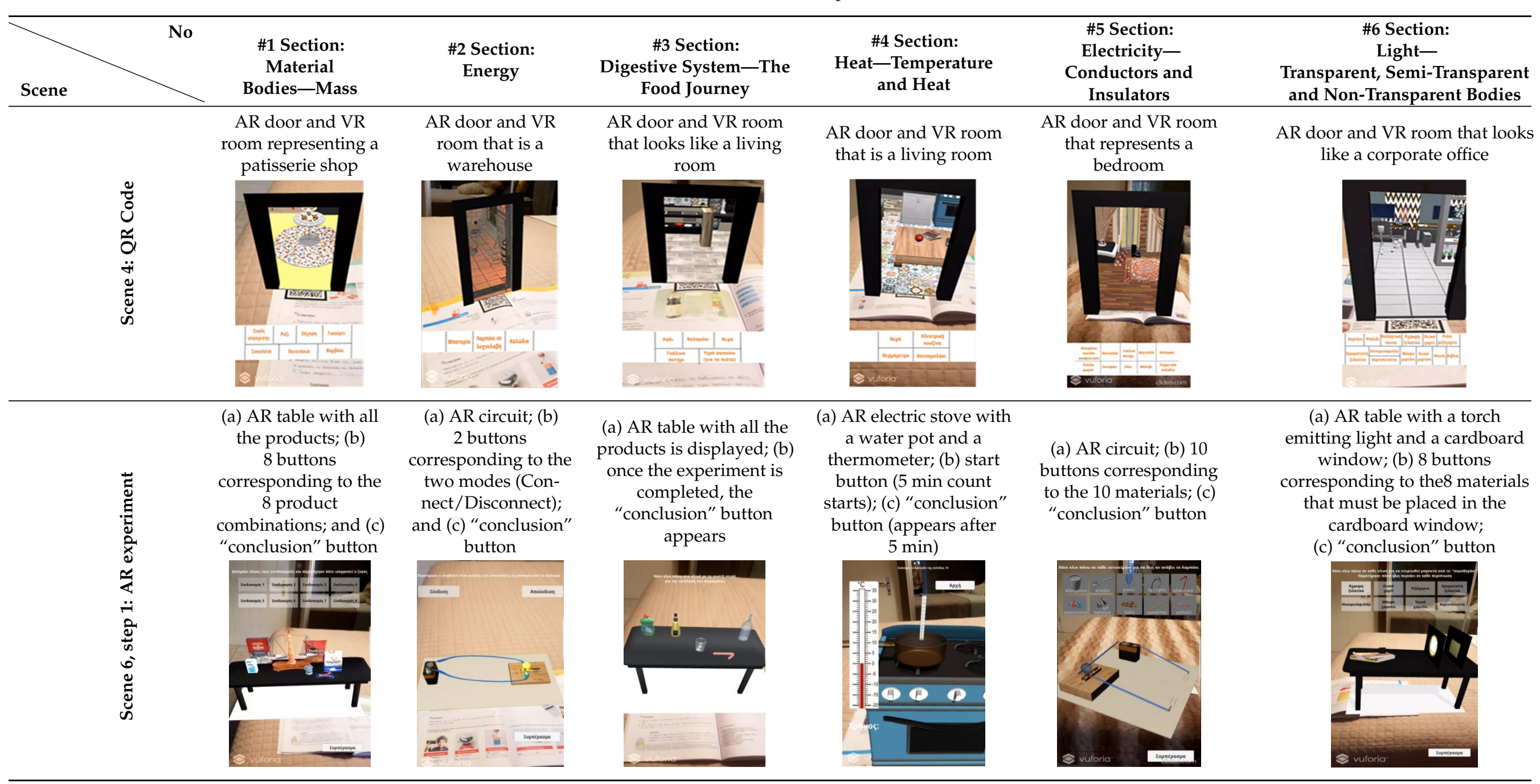


Table 1. Cont.

\begin{tabular}{|c|c|c|c|c|c|c|c|c|}
\hline Scene & & No & $\begin{array}{l}\text { \#1 Section: } \\
\text { Material } \\
\text { Bodies-Mass }\end{array}$ & $\begin{array}{l}\text { \#2 Section: } \\
\text { Energy }\end{array}$ & $\begin{array}{c}\text { \#3 Section: } \\
\text { Digestive System-The } \\
\text { Food Journey }\end{array}$ & $\begin{array}{l}\text { \#4 Section: } \\
\text { Heat-Temperature } \\
\text { and Heat }\end{array}$ & $\begin{array}{l}\text { \#5 Section: } \\
\text { Electricity- } \\
\text { Conductors and } \\
\text { Insulators }\end{array}$ & $\begin{array}{c}\text { \#6 Section: } \\
\text { Light- } \\
\text { Transparent, Semi-Transparent } \\
\text { and Non-Transparent Bodies }\end{array}$ \\
\hline & 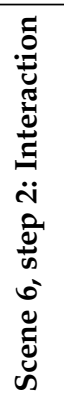 & & $\begin{array}{l}\text { Find } 3 \text { of the } 8 \\
\text { combinations with } \\
\text { which the scale is } \\
\text { balanced }\end{array}$ & $\begin{array}{l}\text { Interact with the AR } \\
\text { circuit and observe } \\
\text { the light bulb in both } \\
\text { situations }\end{array}$ & $\begin{array}{l}\text { Click on the materials in } \\
\text { the correct order to } \\
\text { perform the experiment }\end{array}$ & $\begin{array}{l}\text { Measure the temperature } \\
\text { every minute for } 5 \mathrm{~min}\end{array}$ & $\begin{array}{l}\text { Select each one of the } \\
\text { materials and observe } \\
\text { the behavior of the light } \\
\text { (if the light is on or not) }\end{array}$ & $\begin{array}{l}\text { Click on any material, put it } \\
\text { between the torch and the } \\
\text { cardboard window and notice } \\
\text { how much light passes through }\end{array}$ \\
\hline & 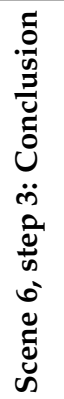 & & $\begin{array}{l}\text { "Mass is a } \\
\text { characteristic property } \\
\text { of all bodies. When the } \\
\text { masses on the scale are } \\
\text { equal, then the scale is } \\
\text { balanced." }\end{array}$ & $\begin{array}{l}\text { "The light does not } \\
\text { illuminate when the } \\
\text { battery is disconnected } \\
\text { from the circuit." }\end{array}$ & $\begin{array}{l}\text { "Liquid dish soap dissolves } \\
\text { oil, as saliva helps break } \\
\text { down food starch and bile } \\
\text { dissolves fats } \\
\text { during digestion." }\end{array}$ & $\begin{array}{l}\text { "Part of the energy is } \\
\text { released when the gas } \\
\text { burns. This part of the } \\
\text { energy is absorbed by the } \\
\text { water. Therefore, the water } \\
\text { temperature rises." }\end{array}$ & $\begin{array}{c}\text { "The materials are classified } \\
\text { into conductors (if the light } \\
\text { is on) and insulators (if the } \\
\text { light is off)." }\end{array}$ & $\begin{array}{c}\text { "Material bodies are characterized } \\
\text { as transparent, semi-transparent } \\
\text { and non-transparent, depending } \\
\text { on the amount of light they allow } \\
\text { to penetrate." }\end{array}$ \\
\hline
\end{tabular}




\section{Two Indicative Examples}

In this section, two indicative examples of the experiments are presented. Firstly, the example of the "Electricity" experiment which belongs to the section of "Conductors and Insulators" is described. This section begins with an introductory stimulus and is followed by an experimental approach. More analytically, the introductory stimulus is presented through a school textbook comic, where "Lampakis" and "Volfraimios" (Tungsten) are the main characters. The following information is provided to the students: the material of which the wire in incandescent bulbs is made is called tungsten. Then, the students are asked to read the dialogues in the comic, in order to describe the problem that Lampakis and Volfraimios are faced with. The problem is that the light bulb of the circuit they made by using a rope instead of a cable does not light up. At the end of the introductory stimulus, the teacher helps the students to make assumptions about possible materials that can be used in a closed electrical circuit, in order to light the bulb.

The experimental approach that follows helps students find out that while some materials allow electricity to flow, others do not. The materials of the experiment appear through some virtual objects, as shown in Table 2.

Table 2. Objects and the materials they are made of for the "Electricity" experiment.

\begin{tabular}{cc}
\hline Object & Material \\
\hline Aluminum refreshment can & Aluminum \\
Spoon & Steel \\
Glass & Glass \\
Ring & Silver \\
Straw & Plastic \\
Baby's dummy & Rubber \\
Beanie & Cloth \\
Wood & Wood \\
Pencil & Graphite \\
Wires & Copper
\end{tabular}

The AR experiment is carried out with the guidance of the book and the teacher. At first, an electrical circuit is displayed above the QR code of the textbook, using the technology of AR. In addition, at the top of the screen, there are ten buttons that correspond to the ten materials/objects of the experiment. By selecting each button, the corresponding object is placed between the connectors of the electrical circuit. The student, after observing the behavior of the light, notes down the materials with which the light can be turned on or not in the provided table of the textbook. The teacher leads a discussion in the class, through which the students will formulate the conclusion. The teacher also introduces the terms of "conductor" and "insulator" and explains them to the students. The teacher then urges them to classify the materials studied in the above experiment into conductors and insulators. Finally, the following conclusion is drawn in the school textbook:

- Conductors: aluminum foil, steel, silver, graphite and copper.

- Insulators: glass, plastic, rubber, cloth and wood.

At the bottom of the screen, there is a "conclusion" button, which leads to the next screen which consists of the conclusion of the experiment, for the students to check the correctness of their answers. After completing the above experiment, the learning objectives that are desired to be achieved by the students are to experimentally establish the existence of conducting and non-conducting materials and to understand the concepts of conductors and insulators.

Another indicative example, which is the experiment of the "Digestive system" experiment which belongs to the section of "The food journey", is presented. Similar to the previous example, it includes two parts, the stimulus and the experiment. In the introductory stimulus, the students are asked to chew bread. Then, it is explained by the teacher that bread contains a substance called starch, and it is stated that saliva breaks down food 
starch. The following experiment helps the students to understand the above introductory stimulus, by drawing a parallel between saliva (which breaks down starch) and liquid dish soap (which breaks down oil).

At first, a table in which all the materials of the experiment are placed is displayed above the QR code of the textbook, using the technology of AR. The goal of the experiment is that the student, after carefully reading the instructions provided by the textbook, has to "click" on the materials placed in the AR table in the correct order. At the top of the screen, there is a text prompting the student to "Click on the materials in the correct order to perform the experiment". The correct order, according to the presentation of the textbook, is: water, oil, straw, liquid dish soap and straw. The experiment consists of the steps shown in Table 3. At first, a glass is filled halfway with water, and then a few drops of oil are added. The students have to mix the solution well with the straw. They should also notice that the oil does not dissolve in the water, but floats on it. In the second phase of the experiment, a small amount of liquid soap is poured into the glass with water and oil, and after mixing well with the straw, it should be observed by the students that after adding the dishwashing liquid, the oil dissolves and mixes with the water. Finally, the students learn the usefulness of saliva for the dissolution of food starch and the usefulness of bile in the function of digestion.

Table 3. The experiment for "Digestive system" step by step.

\begin{tabular}{ccc}
\hline No. of Step & Click on & Action \\
\hline$\# 1$ & Water bottle & Put water into the glass \\
$\# 2$ & Oil & Put oil into the glass \\
$\# 3$ & Straw & Stir the mixture \\
$\# 4$ & Dish soap & Put liquid into the glass \\
$\# 5$ & Straw & Stir the mixture \\
\hline
\end{tabular}

The conclusion is established with appropriate questions and discussion in class. Students should be aware that the effect of liquid dish soap on oil is the same as the effect of bile on food fats. Finally, students are asked to formulate the following conclusion: "Liquid dish soap dissolves oil, as saliva helps break down food starch and bile dissolves fats during digestion". Once step 5 is completed, the "conclusion" button appears at the bottom of the screen, which leads to the screen with the final conclusion. Moreover, students can check if their answers are correct.

All the experiments are available online (Part 1: https://www.youtube.com/watch? $\mathrm{v}=0$ ST0fkDIFEY, accessed 6 August 2021 and Part 2: https:/ /www.youtube.com/watch? $\mathrm{v}=8 j \mathrm{jbmKPim} 5 \mathrm{U}$, accessed 6 August 2021).

\section{Pilot Experiment}

The pilot experiment was conducted through a combination of qualitative and quantitative methods. An unstructured interview along with participant observation was carried out to gather qualitative data. This combination of methods aimed to gain insight about the experience of both students and teachers. Regarding the quantitative method, a questionnaire was administered to all participants aiming to evaluate the system's usability. For the system's usability, we used the system usability scale (SUS) which was developed by Brooke [37] as a quick and dirty survey to evaluate the usability of a given system. The SUS test was used because (a) it provides a single score, (b) it is technology-independent and this makes it quite flexible for the system we had to evaluate, (c) it is easy to handle, (d) the questionnaire is nonproprietary and this makes it cost-effective, (e) it is highly effective in terms of reliability [38] and validity [39], (f) it is translated in Greek [40] and (g) it provides reliable results even with a small sample size [39]. 


\subsection{Participants}

The study took place at an Elementary School of, Thessaloniki, Greece, during the winter period (January 2021). Fourteen (14) students and three (3) teachers participated in the study. The average age of the students was 10 years. The three teachers who took part in the experiment process had extensive teaching experience (more than 10 years).

All students and teachers volunteered to participate in the activity as part of their everyday school activities. Before the experiment took place, there was a training session with the teachers of the classroom about the implementation of the experiment. The experiment was part of the current school curriculum so that the flow of the school curriculum would not be disturbed, and it was performed within the class hour (duration of $45 \mathrm{~min}$ ). The students were randomly assigned to work in dyads, forming seven (7) student groups in total, while teachers participated as instructors.

\subsection{Setting}

Experiments were conducted in classrooms that were offered by schools for this purpose. The classrooms were adequately arranged so that the system was accessible for all students. The system was projected on the whiteboard of the classroom, by the instructor, to be visible to everyone. Additionally, the system was provided to each student group through a smart mobile device.

\subsection{Material and Procedure}

Students, their parents and teachers were informed about the pilot study one week before the experiment. The lesson was started with an introductory stimulus related to the experiment by the teacher/instructor. Then, the instructor provided instructions and guidelines to the students on how to use the system. The execution steps of the experiment were displayed simultaneously on both the whiteboard of the classroom through the projector, and the screen of the mobile of each dyad of students.

Data were collected through an unstructured interview, participant observation and a questionnaire. Specifically, during the experiment, participants were observed regarding how they react and behave. At the end of the experiment, questionnaires were distributed to both students and teachers in printed form and were answered individually. The completion of the questionnaires was conducted in the same classroom, always in visual contact with the system. After that, an unstructured interview was carried out with the three (3) teachers.

The collected data from questionnaires were organized in Microsoft Excel 2019 and were analyzed using IBM SPSS Statistics v23.0. The system usability scale (SUS) test was translated in Greek and was administered to the students in printed form after the interaction with the system.

\section{Results and Discussion}

\subsection{Evaluation of Quantitative Method}

The data collected from the questionnaires in the pilot, along with the mean values and standard deviations for the students and teachers in each question, are presented in Table 4. The overall SUS score was 84.642 (sd 5.773) for the students, while the score for the teachers was 78.333 (sd 10.735). In both cases, the score is quite satisfactory and shows that the system was quite usable for both students and teachers. 
Table 4. Mean values and standard deviations of students' and teachers' responses.

\begin{tabular}{|c|c|c|c|}
\hline Item & English Version of SUS & $\begin{array}{c}\text { Student } \\
\text { Responses } \\
\text { Mean (Std) }\end{array}$ & $\begin{array}{c}\text { Teacher } \\
\text { Responses } \\
\text { Mean (Std) }\end{array}$ \\
\hline Q1 & $\begin{array}{l}\text { I think that I would like to use this } \\
\text { system frequently }\end{array}$ & $4.071(0.997)$ & $4.6667(0.577)$ \\
\hline Q2 & I found the system unnecessarily complex & $1.285(0.611)$ & $1.6667(0.577)$ \\
\hline Q3 & I thought the system was easy to use & $4.5(0.854)$ & $4.0000(0.000)$ \\
\hline Q4 & $\begin{array}{l}\text { I think that I would need the support of a } \\
\text { technical person to be able to use } \\
\text { this system }\end{array}$ & $1.785(1.050)$ & $2.3333(1.527)$ \\
\hline Q5 & $\begin{array}{l}\text { I found the various functions in this system } \\
\text { were well integrated }\end{array}$ & $4.571(0.646)$ & $4.0000(0.000)$ \\
\hline Q6 & $\begin{array}{l}\text { I thought there was too much inconsistency } \\
\text { in this system }\end{array}$ & $1.785(1.050)$ & $2.3333(0.577)$ \\
\hline Q7 & $\begin{array}{l}\text { I would imagine that most people would } \\
\text { learn to use this system very quickly }\end{array}$ & $4.714(0.468)$ & $4.3333(0.577)$ \\
\hline Q8 & I found the system very cumbersome to use & $1.357(0.497)$ & $1.6667(0.577)$ \\
\hline Q9 & I felt very confident using the system. & $4.428(0.755)$ & $4.0000(1.000)$ \\
\hline Q10 & $\begin{array}{l}\text { I needed to learn a lot of things before I } \\
\text { could get going with this system. }\end{array}$ & $2.214(1.476)$ & $2.3333(0.577)$ \\
\hline
\end{tabular}

More analytically, the average SUS score of the ARGBL application is acceptable for teachers (over 75), while the score for students is relatively high (84.642). This could be explained by the fact that the system worked properly. Although the experiment was successful for both students and teachers, there was a concern about how the students would manage to use the system to conduct the physics experiment. The fact that students are familiar with such devices along with the daily usage of them made it easier for them to handle the device and successfully complete the experiment. However, this led the students to ask questions about the process of the experiment, e.g., how to collect the experiments' materials from the VR room. Although there were written instructions on the screen, students were overwhelmed by the virtual world and, as a result, did not read them. A possible solution to this could be the use of tablets, since the instructions on bigger screens might easily be "caught by the eye".

\subsection{Evaluation of Qualitative Method}

Based on the observation data, we noticed that most of the students had the curiosity to try new activities, including conducting experiments using the AR technology through smart devices. Therefore, teachers should try innovative instructional methods, tailored to new requirements relating to the ARGBL application. It is worth mentioning that teachers should conduct a training session for students about how to use the system and how to interact with the $\mathrm{QR}$ code, before the experiment takes place. In addition, the performance of $\mathrm{QR}$ code recognition is mainly based on lighting conditions. The virtual objects formed under weak light conditions may twinkle at times. As a result, teachers are required to adapt the classroom properly in terms of lighting.

According to the unstructured interview with the teachers about their experience, they supported that the group of two students rather than larger groups is more preferable. It was also mentioned that small groups (two or three students) work better than larger groups, not only in the collaboration between the team members but also in the time that the system is used by each member, a fact that positively triggers students' motivation, engagement and teamwork. Nonetheless, groups of two students would require a lot of equipment (number of smart devices), in the case of a larger sample. Last but not least, the teachers agreed on the fact that the ARGBL application is more advantageous, since it can run offline, without the need of an internet connection. This makes it a lot easier to be used in areas of limited WiFi or data connectivity, such as schools. The students can use the ARGBL application instantly without any delays or internet difficulties. On the 
other hand, applications that work offline do not provide the functionality of interaction to users. In the ARGBL application, the interaction between users is conducted face to face in a classroom. This means that a discussion between the students as well as between the teacher and the students is necessary to evolve the learning process.

\section{Conclusions and Future Work}

Leveraging the aforementioned findings, an ARGBL application was proposed for the implementation of physics experiments in the fifth grade of a Greek primary school. The application is both educational and entertaining, since the students have to conduct a physics experiment by playing an AR treasure hunt game. A pilot experiment was conducted, and a questionnaire was administered to all participants, both students and teachers, in order to investigate the usability of the system. Moreover, this study explored the opinions and the preferences of the participants by the process of unstructured interviews and observations. The results of the pilot experiment are very promising, since the system's usability was satisfactory, revealing that the proposed ARGBL application can provide added value to the educational community. More specifically, what we learned, which is in accordance with the literature review, is that students had a positive attitude towards using the system for their learning process since they fully engaged with it $[15,28,30]$. In addition, both teachers and students supported that the use of the ARGBL application can attract students attention and increase their learning motivation $[10,29,30,33]$ in the physics course. Finally, a well-structured experiment should be followed by the teachers, including a training session of how students can use the system, how they can interact with the QR code and what the process of the experiment is.

However, the proposed system has some limitations that merit further consideration in future work. Firstly, although our analysis is robust in small samples, a larger-scale experiment is necessary. In the midst of the COVID-19 pandemic, it was hard to have an adequate sample size, due to fact that the Greek schools, most of the school year, were closed. Secondly, the ARGBL application refers to a specific subject, namely, physics experiments in the fifth grade of a Greek primary school; therefore, the research results cannot be generalized to other learning topics and to other age groups. Therefore, our future plans are to extend the learning content of our proposed ARGBL application to other age groups by adding more exercises and experiments. Additionally, a long-term experiment would be necessary to further investigate the usability of the system and to extract valuable results about the learning outcomes of the students.

Author Contributions: M.Z. implemented the application and, together with C.V., E.K., T.S., conceived, designed and wrote this paper. All authors have read and agreed to the published version of the manuscript.

Funding: This research received no external funding.

Institutional Review Board Statement: The study was conducted according to the guidelines of the Declaration of Helsinki and followed the regulations of the National Bioethics Committee. In our study the issue of personal data protection was confronted by keeping the anonymity of the participants, while informed con-sent was obtained.

Informed Consent Statement: Informed consent was obtained from all subjects involved in the study.

Data Availability Statement: The data presented in this study are available on request from the corresponding author.

Acknowledgments: The authors of the paper wish to warmly thank the anonymous reviewers for their constructive comments, along with the teachers and director of the school for the hospitality and support offered.

Conflicts of Interest: The authors declare no conflict of interest. 


\section{References}

1. Azuma, R.T. A Survey of Augmented Reality. Presence Teleoperators Virtual Environ. 1997, 6, 355-385. [CrossRef]

2. Makhataeva, Z.; Varol, H.A. Augmented Reality for Robotics: A Review. Robotics 2020, 9, 21. [CrossRef]

3. Hantono, B.S.; Nugroho, L.E.; Santosa, P.I. Meta-Review of Augmented Reality in Education. In Proceedings of the 10th International Conference on Information Technology and Electrical Engineering (ICITEE), Kuta, Bali, $24-26$ July 2018.

4. ARCore. Available online: https://developers.google.com/ar (accessed on 15 February 2021).

5. Apple Developer, Augmented Reality. Available online: https://developer.apple.com/augmented-reality/ (accessed on 20 March 2021).

6. Unity, Augmented Reality. Available online: https://unity.com/unity/features/ar (accessed on 30 August 2021).

7. Li, J.; van der Spek, E.D.; Feijs, L.; Wang, F.; Hu, J. Augmented Reality Games for Learning: A Literature Review. In Distributed, Ambient and Pervasive Interactions. DAPI 2017. Lecture Notes in Computer Science; Streitz, N., Markopoulos, P., Eds.; Springer: Cham, Switzerland, 2017; Volume 10291. [CrossRef]

8. Billinghurst, M.; Duenser, A. Augmented Reality in the Classroom. Computer 2012, 45, 56-63. [CrossRef]

9. Cubillo, J.; Martin, S.; Castro, M.; Boticki, I. Preparing augmented reality learning content should be easy: UNED ARLE-An authoring tool for augmented reality learning environments. Comput. Appl. Eng. Educ. 2015, 23, 778-789. [CrossRef]

10. Fotaris, P.; Pellas, N.; Kazanidis, I.; Smith, P. A systematic review of augmented reality game-based applications in primary education. In Proceedings of the 11th European Conference on Game-Based Learning, Graz, Austria, 5-6 October 2017.

11. Diegmann, P.; Schmidt-Kraepelin, M.; Eynden, S.V.; Basten, D. Benefits of Augmented Reality in Educational Environments-A Systematic Literature Review. In Proceedings of the International Conference of Wirtschaftsinformatik, Osnabrück, Germany, 4-6 March 2015.

12. Johnson, L.; Smith, R.; Willis, H.; Levine, A.; Haywood, K. The 2011 Horizon Report; The New Media Consortium: Austin, TX, USA, 2011.

13. Broll, W.; Lindt, I.; Herbst, I.; Ohlenburg, J.; Braun, A.K.; Wetzel, R. Toward next-gen mobile AR games. Comput. Graph. Appl. IEEE 2008, 28, 40-48. [CrossRef]

14. Klopfer, E.; Squire, K. Environmental detectives: The development of an augmented reality platform for environmental simulations. Educ. Technol. Res. Dev. 2008, 56, 203-228. [CrossRef]

15. Enyedy, N.; Danish, J.A.; Delacruz, G.; Kumar, M. Learning physics through play in an augmented reality environment. Int. J. Comput.-Support. Collab. Learn. 2012, 7, 347-378. [CrossRef]

16. Arvanitis, T.N.; Petrou, A.; Knight, J.F.; Savas, S.; Sotiriou, S.; Gargalakos, M.; Gialouri, E. Human factors and qualitative pedagogical evaluation of a mobile augmented reality system for science education used by learners with physical disabilities. Pers. Ubiquitous Comput. 2007, 13, 243-250. [CrossRef]

17. Pritami, F.A.; Muhimmah, I. Digital Game Based Learning Using Augmented Reality for Mathematics Learning. In Proceedings of the 7th International Conference on Software and Computer Applications, Kuantan, Malaysia, 8-10 February 2018; Association for Computing Machinery: New York, NY, USA, 2018; pp. 254-258.

18. de Carvalho, C.V. Is game-based learning suitable for engineering education? In Proceedings of the 2012 IEEE Global Engineering Education Conference (EDUCON), Marrakesh, Morocco, 17-20 April 2012. [CrossRef]

19. Pellas, N.; Fotaris, P.; Kazanidis, I.; Wells, D. Augmenting the learning experience in primary and secondary school education: A systematic review of recent trends in augmented reality game-based learning. Virtual Real. 2019, 23, 329-346. [CrossRef]

20. Atwood-Blaine, D.; Hufman, D. Mobile gaming and student interactions in a science center: The future of gaming in science education. Int. J. Sci. Math. Educ. Suppl. 2017, 1, 45-65. [CrossRef]

21. Hung, Y.H.; Chen, C.H.; Huang, S.W. Applying augmented reality to enhance learning: A study of different teaching materials. J. Comput. Assist. Learn. 2017, 33, 252-266. [CrossRef]

22. Hsiao, H.S.; Chang, C.S.; Lin, C.Y.; Wang, Y.Z. Weather observers: A manipulative augmented reality system for weather simulations at home, in the classroom, and at museum. Interact. Learn. Environ. 2013, 24, 205-223. [CrossRef]

23. Echeverría, A.; Améstica, M.; Gil, F.; Nussbaum, M.; Barrios, E.; Leclerc, S. Exploring different technological platforms for supporting co-located collaborative games in the classroom. Comput. Hum. Behav. 2012, 28, 1170-1177. [CrossRef]

24. Furió, D.; González-Gancedo, S.; Juan, M.C.; Seguí, I.; Rando, N. Evaluation of learning outcomes using an educational iPhone game vs. traditional game. Comput. Educ. 2013, 64, 1-23. [CrossRef]

25. Chen, C.H.; Chou, Y.Y.; Huang, C.Y. An augmented-reality-based concept map to support mobile learning for science. Asia-Pac. Educ. Res. 2016, 25, 567-578. [CrossRef]

26. Chiang, T.H.C.; Yang, S.J.H.; Hwang, G.J. An augmented reality-based mobile learning system to improve students' learning achievements and motivations in natural science inquiry activities. Educ. Technol. Soc. 2014, 17, 352-365.

27. Ruiz-Ariza, A.; Casuso, R.A.; Suarez-Manzano, S.; Martínez-López, E.J. Effect of augmented reality game Pokémon GO on cognitive performance and emotional intelligence in adolescent young. Comput. Educ. 2017, 116, 49-63. [CrossRef]

28. Cai, S.; Chiang, F.; Wang, X. Using the Augmented Reality 3D Technique for a Convex Imaging Experiment in a Physics Course. Int. J. Eng. Educ. 2013, 29, 856-865.

29. Cai, S.; Chiang, F.; Sun, Y.; Lin, C.; Lee, J. Applications of augmented reality-based natural interactive learning in magnetic field instruction. Interact. Learn. Environ. 2016, 25, 778-791. [CrossRef] 
30. Zhang, J.; Sung, Y.T.; Hou, H.T.; Chang, K.E. The development and evaluation of an augmented reality-based armillary sphere for astronomical observation instruction. Comput. Educ. 2014, 73, 178-188. [CrossRef]

31. Cai, S.; Wang, X.; Chiang, F.K. A case study of augmented reality simulation system application in a chemistry course. Comput. Hum. Behav. 2014, 37, 31-40. [CrossRef]

32. Efstathiou, I.; Kyza, E.; Georgiou, Y. An inquiry-based augmented reality mobile learning approach to fostering Primary school students' historical reasoning in non-formal settings. Interact. Learn. Environ. 2017, 26, 22-41. [CrossRef]

33. Tobar-Muñoz, H.; Baldiris, S.; Fabregat, R. Augmented reality game-based learning: Enriching students' experience during reading comprehension activities. J. Educ. Comput. Res. 2017, 55, 901-936. [CrossRef]

34. Di Serio, A.; Ibáñez, M.B.; Kloos, C.D. Impact of an augmented reality system on students' motivation for a visual art course Comput. Educ. 2013, 68, 586-596. [CrossRef]

35. Tobar-Muñoz, H.; Baldiris, S.; Fabregat, R. Co Design of Augmented Reality Game-Based Learning Games with Teachers Using Co-CreaARGBL Method. In Proceedings of the 16th International Conference on Advanced Learning Technologies (ICALT), Austin, TX, USA, 25-28 July 2016. [CrossRef]

36. Unity Platform. Available online: https://unity.com/products/unity-platform (accessed on 15 November 2020).

37. Brooke, J. SUS: A “quick and dirty" usability scale. In Usability Evaluation in Industry; Jordan, P.W., Thomas, B., Weerdmeester, B.A., McClelland, I.L., Eds.; Taylor \& Francis: London, UK, 1996; pp. 189-194.

38. Bangor, A.; Kortum, P.T.; Miller, J.T. An Empirical Evaluation of the System Usability Scale. Intl. J. Hum.-Comput. Interact. 2008, 24, 574-594. [CrossRef]

39. Tullis, T.S.; Stetson, J.N. A Comparison of Questionnaires for Assessing Website Usability. In Proceedings of the Usability Professionals Association (UPA), Minneapolis, MN, USA, 7-11 June 2004.

40. Katsanos, C.; Tselios, N.; Xenos, M. Perceived usability evaluation of learning management systems: A first step towards standardization of the System Usability Scale in Greek. In Proceedings of the 16th Pan-Hellenic Conference on Informatics, PCI 2012, Piraeus, Greece, 5-7 October 2012; IEEE CPS: Piscataway, NJ, USA, 2012. 